\title{
POTENCIAL DE CONTAMINAÇÃO DA ÁGUA SUBTERRÂNEA POR PESTICIDAS NA BACIA DO RIO DOURADOS, MS
}

RÔMULO PENNA SCORZA JÚNIOR*

JOÃO PAULO DA SILVA**

\begin{abstract}
Este trabalho teve os seguintes objetivos: (i) elaborar base de dados contendo informações sobre o uso de pesticidas na Bacia Hidrográfica do Rio Dourados (BHRD), MS; ii) simular a lixiviação dos principais pesticidas utilizados na BHRD por meio do simulador PEARL; e iii) gerar "ranking" dos principais pesticidas utilizados na BHRD com relação ao seu potencial de contaminação das águas subterrâneas. A base de dados foi composta por 4.374 receituários agronômicos, emitidos no ano de 2002. Os dados de entrada para o simulador PEARL foram determinados experimentalmente ou obtidos na literatura. As simulações foram realizadas considerando o período de 19 anos, obtendo-se as concentrações na fase líquida do solo a 2, 5 e $10 \mathrm{~m}$ de profundidade e profundidades máximas de lixiviação. Os pesticidas mais usados na BHRD foram o glifosato, seguido em ordem decrescente pelo 2,4-D, fipronil, metamidofós, imazaquim, parationa metílica, trifluralina e atrazina. As simulações revelaram que os pesticidas com maior potencial de contaminação da água subterrânea na BHRD foram o bentazona, imazetapir, fomesafem, 2,4-D, metamidofós, imazaquim, tiodicarbe e monocrotofós.
\end{abstract}

PALAVRAS-CHAVE: CONTAMINAÇÃO AMBIENTAL; PESTICIDAS; RIO DOURADOS; PEARL; LIXIVIAÇÃO.

* Ph. D. em Ciências Ambientais, Pesquisador da Embrapa Agropecuária Oeste, Dourados, MS (e-mail: romulo@cpao.embrapa.br).

** Acadêmico do curso de Ciência da Computação da Universidade Estadual de Mato Grosso do Sul, Dourados, MS (e-mail: s.joaopaulo@gmail.com). 


\section{INTRODUÇÃO}

A preservação da qualidade dos recursos hídricos é de fundamental importância para garantir o acesso à água potável para as gerações atual e futura. A agricultura moderna faz uso intensivo de pesticidas (herbicidas, inseticidas, fungicidas, nematicidas e outros), que podem trazer sérios riscos à contaminação das águas subterrânea e superficial.

Os pesticidas são aplicados sobre as plantas ou diretamente no solo. Mesmo quando aplicados sobre as plantas, cerca de $50 \%$ da dose poderá ter como destino final o solo, independentemente da forma como for realizada essa aplicação (CHAIM et al., 1999). Após chegar ao solo, o pesticida pode ter seu destino influenciado por dois principais tipos de transporte: lixiviação e escoamento superficial (LAVORENTI, PRATA REGITANO, 2003). A importância e a magnitude desses tipos de transporte depende de fatores como, tipo de solo, topografia, características físicoquímicas dos pesticidas, práticas de manejo do solo, condições climáticas, etc. A lixiviação tem sido apontada como a principal causadora da contaminação de água subterrânea (FLURY, 1996). CARTER (2000) relata que o transporte de pesticidas por lixiviação pode chegar a $1 \%$ da dose aplicada e, em casos excepcionais a 5\%. Já com relação ao escoamento superficial, numa única chuva esse transporte pode variar de 1 a $2 \%$ da dose aplicada (WAUCHOPE, 1978).

Problemas de contaminação dos recursos hídricos por pesticidas têm sido relatados no mundo todo (DOMAGALSKI e DUBROVSKY, 1992; BOTTONI e FUNARI, 1992; SCORZA JÚNIOR et al., 2004). Diante das crescentes evidências de contaminação dos recursos hídricos por pesticidas torna-se urgente avaliar o risco de contaminações futuras. A grande diversidade de solos, clima e pesticidas utilizados na agricultura inviabiliza a realização de inúmeros experimentos em condições de campo para atender todas essas combinações (solo $x$ clima $x$ pesticidas). Essa limitação tem estimulado o uso de modelos matemáticos e simuladores para prever o destino de pesticidas nos solos, possibilitando grande economia de tempo e recursos financeiros. A utilização da técnica de modelagem matemática e simulação possibilita a integração do conhecimento de forma organizada, gerando resultados conclusivos e possibilitando o estudo das interações que ocorrem entre os processos que compõem o sistema estudado (PESSOA et al., 1997). Suas vantagens incluem baixo custo quando comparado à experimentação em condições de campo, rapidez na obtenção dos resultados, e possibilidade de gerar informações completas e de se estudar cenários diversificados.

Os simuladores para lixiviação de pesticidas em solos são classificados quanto aos seus propósitos em três diferentes categorias: triagem ou "screening", regulamentação e pesquisa (COHEN et al., 1995). LOURENCETTI et al. (2005) comparou o potencial de lixiviação de alguns pesticidas utilizando os critérios da EPA (COHEN, 1995) e os modelos de GUS (GUSTAFSON, 1989), LIX (SPADOTTO, 2002), RF e AF (RAO, HORNSBY e JESSUP, 1985) e TLPI (PARAÍBA e SPADOTTO, 2002). Todos esses modelos são bastante simplistas, sendo classificados como modelos ou simuladores de triagem. Geralmente, esses modelos assumem que o coeficiente de sorção e o fluxo de água no solo são constantes em função da profundidade e ignoram a absorção de pesticidas pelas raízes das plantas e os processos de difusão e dispersão. LOURENCETTI et al. (2005) observaram que os resultados do potencial de lixiviação dos pesticidas testados com base nos modelos não foram concordantes para alguns pesticidas. No entanto, suas classificações quanto ao potencial de lixiviação foram bastante semelhantes quando se compara os pesticidas entre si. Com a facilidade de acesso a computadores com grande capacidade de armazenamento/ processamento de dados e da maior disponibilidade de dados relativos à caracterização dos solos e clima, simuladores mais complexos têm sido utilizados para avaliação do potencial de lixiviação de pesticidas (LEISTRA et al., 2002; LARSBO e JARVIS, 2003; MALONE et al., 2004). O simulador PEARL (LEISTRA et al., 2002; TIKTAK et al., 2002) tem sido empregado pelos países membros da Comunidade Européia para avaliação dos riscos de contaminação dos recursos hídricos por pesticidas. 
Este trabalho teve como objetivos desenvolver base de dados contendo informações sobre o uso de pesticidas na Bacia Hidrográfica do Rio Dourados (BHRD) e simular a lixiviação dos principais pesticidas utilizados na BHRD empregando o simulador PEARL.Também pretendeu-se gerar "ranking" dos principais pesticidas utilizados na BHRD com relação ao seu potencial de contaminação das águas subterrâneas.

\section{MATERIAL E MÉTODOS}

\subsection{BANCO DE DADOS SOBRE O USO DE PESTICIDAS NA BHRD}

Para obtenção das informações sobre o uso de pesticidas na Bacia do Rio Dourados (MS) foram analisados 4.374 receituários agronômicos, emitidos no ano de 2002 para os 12 municípios componentes da BHRD (Antônio João, Caarapó, Deodápolis, Dourados, Fátima do Sul, Glória de Dourados, Itaporã, Ivinhema, Jateí, Laguna Carapã, Ponta Porã e Vicentina). O acesso aos receituários agronômicos foi disponibilizado pelo Conselho Regional de Engenharia, Arquitetura e Agronomia de Mato Grosso do Sul (CREA/MS), Campo Grande, MS. As informações extraídas dos receituários foram inseridas em base de dados elaborada em MS-ACCESS ${ }^{\odot}$, utilizando-se a metodologia Relacional, mediante relacionamento de tabelas sobre: (i) municípios componentes da BHRD; (ii) nome comercial do pesticida; (iii) princípio ativo do pesticida; (iv) classe; (v) classe toxicológica; (vi) culturas e (vii) fabricante.

\subsection{DESCRIÇÃO TEÓRICA DO SIMULADOR PEARL}

O simulador PEARL, versão 3.3.3 (LEISTRA et al., 2002; TIKTAK et al., 2002) tem como objetivo principal simular a lixiviação de pesticidas em solos mediante integração de diversos fatores que atuam de forma direta e indireta nesse tipo de transporte (como, por exemplo, os atributos químicos e físicos do solo, o clima e as características físico-químicas das moléculas de pesticidas). Para descrever o fluxo da água e a temperatura no solo, o PEARL conta com o simulador SWAP (VAN DAM et al., 1997). Esse simulador descreve o fluxo da água no solo utilizando a equação de Darcy considerando fluxo unidimensional, vertical e transiente. A combinação da equação de Darcy com a de continuidade resulta na equação de Richards (1).

$$
\frac{\partial \theta}{\partial t}=\frac{\partial}{\partial z}\left[K\left(\frac{\partial h}{\partial z}+1\right)\right]-S
$$

Em que: $\theta=$ umidade volumétrica do solo $\left(\mathrm{cm}^{3} \mathrm{~cm}^{-3}\right), \mathrm{t}=$ tempo (dia), $\mathrm{K}=$ condutividade hidráulica $(\mathrm{cm} \mathrm{dia-1}), \mathrm{h}=$ potencial da água no solo $(\mathrm{cm}), \mathrm{z}=$ profundidade $(\mathrm{cm})$ e $\mathrm{S}=$ taxa de absorção de água pelas raízes das plantas $\left(\mathrm{dia}^{-1}\right)$. A relação entre a umidade do solo e o seu potencial (curva de retenção) é descrita pelo modelo de VAN GENUCHTEN (1980):

$$
\theta(h)=\theta_{r}+\frac{\theta_{s}-\theta_{r}}{\left(1+|\alpha h|^{n}\right)^{1-1 / n}}
$$

Em que: $\theta_{\mathrm{r}}=$ umidade volumétrica residual $\left(\mathrm{cm}^{3} \mathrm{~cm}^{-3}\right), \theta_{\mathrm{s}}=$ umidade volumétrica saturada $\left(\mathrm{cm}^{3}\right.$ $\left.\mathrm{cm}^{-3}\right)$ e $\alpha\left(\mathrm{cm}^{-1}\right)$ e $n(-)=$ parâmetros obtidos após ajuste do modelo aos dados observados da curva de retenção. Já a relação entre condutividade hidráulica em meio não-saturado e o potencial da água no solo é descrita pelo modelo de MUALEM (1976): 


$$
K(h)=K_{s} \frac{\left[\left(1+|\alpha h|^{n}\right)^{1-1 / n}-|\alpha h|^{n-1}\right]^{2}}{\left(1+|\alpha h|^{n}\right)^{(1-1 / n)(\lambda+2)}}
$$

Em que: $\mathrm{K}_{\mathrm{s}}=$ condutividade hidráulica em meio saturado $\left(\mathrm{cm} \mathrm{dia}^{-1}\right)$ e $\lambda(-)=$ parâmetro obtido após ajuste do modelo aos dados observados. A taxa de absorção de água pelas raízes, $\mathrm{S}\left(\mathrm{dia}^{-1}\right)$, conforme FEDDES, KOWALIK e ZARADNY, 1978) é dada por:

$$
S=\alpha_{\text {red }} \cdot S_{P}
$$

Em que: $\alpha_{\text {red }}=$ fator de redução adimensional e $S_{p}=$ taxa potencial de absorção de água pelas raízes $\left(\right.$ dia $\left.^{-1}\right)$ obtida por:

$$
S_{p}=\frac{T_{P}}{d_{r}}
$$

Em que: $T_{P}=$ taxa de transpiração potencial $\left(\mathrm{cm} \mathrm{dia}^{-1}\right)$ e $d_{r}=$ espessura da camada radicular $(\mathrm{cm})$.

O cálculo da taxa de evapotranspiração potencial, $E T_{P}\left(\mathrm{~cm} \mathrm{dia}{ }^{-1}\right)$, é necessário para quantificar as condições de contorno na superfície do solo e o valor de $S_{P}$. $E T_{P}$ é calculado pela equação de Penman-Monteith (MONTEITH, 1965; VAN DAM et al., 1997). Com isso, $T_{P}$ (cm dia-1) é obtido por:

$$
T_{P}=\left(1-f_{w}\right) \cdot E T_{P}-E_{P}
$$

Em que: $\mathrm{f}_{w}=$ fração do dia em que a cobertura foliar está molhada $(-)$ e $E_{p}\left(\mathrm{~cm} \mathrm{dia}^{-1}\right)=$ taxa de evaporação potencial da água no solo, calculada por:

$$
E_{P}=e^{-\star I A F} \cdot E T_{P}
$$

Em que: $\kappa=$ coeficiente de extinção da radiação solar global (-) e o IAF = índice de área foliar (-).

A temperatura do solo é obtida utilizando-se a combinação da Lei de Fourier e a equação de conservação de calor no solo. A concentração total do pesticida no solo, $C^{*}\left(\mathrm{~g} \mathrm{~cm}^{-3}\right)$, é definida pela soma da concentração na fase sólida, líquida e gasosa:

$$
C^{*}=\theta \cdot C_{L}+\rho \cdot X+\varepsilon \cdot C_{G}
$$

Em que: $C_{L}=$ concentração do pesticida na fase líquida do solo $\left(\mathrm{g} \mathrm{cm}^{-3}\right), \rho=$ densidade aparente do solo $\left(\mathrm{g} \mathrm{cm}^{-3}\right), X=$ concentração do pesticida na fase sólida do solo $\left(\mathrm{g} \mathrm{g}^{-1}\right), \varepsilon=$ fração gasosa do solo $\left(\mathrm{cm}^{3} \mathrm{~cm}^{-3}\right)$ e $\mathrm{C}_{\mathrm{G}}=$ concentração do pesticida na fase gasosa do solo $\left(\mathrm{g} \mathrm{cm}^{-3}\right)$. A sorção do pesticida na fase sólida do solo é descrita pela isoterma de Freundlich: 


$$
X=m_{O M} \cdot K_{O M} \cdot C_{L, R E F}\left(\frac{C_{L}}{C_{L, R E F}}\right)^{N}
$$

Em que: $m_{O M}=$ fração da matéria orgânica no solo $(-), K_{O M}=$ coeficiente de partição do pesticida entre a matéria orgânica e a solução do solo $\left(\mathrm{cm}^{3} \mathrm{~g}^{-1}\right), C_{L, R E F}=$ valor de referência para $C_{L}$ (definido como $1 \mathrm{mg} \mathrm{L}^{-1}$ ) utilizado com o objetivo de evitar que a unidade de $K_{O M}$ seja dependente do expoente $\mathrm{N}$ de Freundlich. A relação entre $K_{O M}$ e o coeficiente de partição do pesticida entre o carbono orgânico e a solução do solo, $\mathrm{K}_{\mathrm{oc}}$, é dada por:

O fluxo de massa do pesticida no solo, $\mathrm{J}\left(\mathrm{g} \mathrm{cm}^{-2} \mathrm{dia}^{-1}\right)$, é descrito considerando os mecanismos de convecção, dispersão e difusão na fase líquida e apenas difusão na fase gasosa, dado por:

$$
J=q \cdot C_{L}-D_{L} \cdot \frac{\partial C_{L}}{\partial z}-D_{G} \cdot \frac{\partial C_{G}}{\partial z}
$$

Em que: $q=$ densidade do fluxo de água $\left(\mathrm{cm} \mathrm{dia}^{-1}\right), D_{L}=$ coeficiente de dispersão hidrodinâmica $\left(\mathrm{cm}^{2}\right.$ dia $\left.^{-1}\right)$ e $D_{G}=$ coeficiente de difusão gasosa $\left(\mathrm{cm}^{2}\right.$ dia $\left.^{-1}\right)$. Os coeficientes $D_{G}$ e $D_{L}$ são calculados pelas equações 12 e 13:

$$
\begin{gathered}
D_{L}=L_{d s} \cdot|g|+\xi_{L} \cdot D_{W} \\
D_{G}=\xi_{G} \cdot D_{A}
\end{gathered}
$$

Em que: $L_{\text {dis }}=$ dispersividade $(\mathrm{cm}), D_{W}=$ coeficiente de difusão do pesticida em água $\left(\mathrm{cm}^{2} \mathrm{dia}^{-1}\right)$, $D_{A}=$ coeficiente de difusão do pesticida no $\operatorname{ar}\left(\mathrm{cm}^{2}\right.$ dia $\left.^{-1}\right)$ e $\xi_{L}$ e $\xi_{G}=$ coeficientes de tortuosidade adimensionais para difusão do pesticida em meio líquido e gasoso, respectivamente.

A taxa de degradação de pesticidas no solo, $R_{T}\left(\mathrm{~g} \mathrm{~cm}^{3} \mathrm{dia}^{-1}\right)$, é descrita por equação de primeira ordem:

$$
R_{T}=\frac{d C^{*}}{d t}=k \cdot C^{*}
$$

Em que: $k$ = coeficiente da taxa de degradação do pesticida no solo $\left(\right.$ dia $\left.^{-1}\right)$. $O$ efeito dos fatores ambientais (temperatura, umidade e profundidade) na degradação do pesticida no solo é calculado por:

$$
k=f_{T} \cdot f_{\theta} \cdot f_{Z} \cdot \frac{\ln (2)}{D T 50_{R K F}}
$$

Em que: $f_{T}, f_{\theta}$ e $f_{Z}=$ coeficientes de redução adimensionais para contabilizar o efeito da temperatura, umidade e profundidade do solo, respectivamente. $D T 50_{R E F}=$ valor de meia-vida do pesticida nas condições de referência, ou seja, solo coletado nos primeiros $30 \mathrm{~cm}$ de profundidade e incubado a $20^{\circ} \mathrm{C}$ e umidade volumétrica correspondente ao potencial mátrico de $10 \mathrm{kPa} \cong 100 \mathrm{~cm}$ de coluna de água). O coeficiente de redução devido ao efeito da temperatura, $f_{T}$, é calculado pela equação de Arrhenius: 
Em que: $U$ = energia de ativação $\left(\mathrm{kJ} \mathrm{mol}^{-1}\right), G=$ constante universal dos gases $\left(\mathrm{kJ} \mathrm{mol}^{-1} \mathrm{~K}^{-1}\right), T=$ temperatura do solo (K) e $T_{R E F}=T$ nas condições de referência (K), ou seja, a $20^{\circ} \mathrm{C}$. Com relação ao efeito da umidade do solo, o coeficiente de redução é dado por:

$$
f_{\theta}=\min \left[1,\left(\frac{\theta}{\theta_{R E F}}\right)^{B}\right]
$$

Em que: $\min =$ o menor valor, $\theta_{R E F}=$ umidade volumétrica correspondente a $10 \mathrm{kPa}$, ou seja, na condição de referência e $B=$ uma constante. Com base na Equação (17) não há influência da umidade do solo na degradação do pesticida quando o solo está com umidade superior a $\theta_{R E F^{*}} \mathrm{O}$ fator $\mathrm{f}_{\mathrm{z}}$ não é definido por equação, mas seus valores podem ser especificados para cada horizonte do solo.

A taxa de absorção de pesticidas pelas raízes das plantas, $R_{U}\left(\mathrm{~g} \mathrm{~cm}^{-3}\right.$ dia-1), é descrita como processo passivo e controlado pela taxa de absorção de água pelas raízes:

$$
R_{U}=S \cdot f_{u} \cdot C_{L}
$$

Em que: $f_{u}=$ fator de concentração na corrente transpiratória (-).

A equação de conservação de massa do pesticida no solo no simulador PEARL é dada por:

$$
\frac{\partial C^{*}}{\partial t}=\frac{\partial}{\partial z}\left(q \cdot C_{L}-D_{L} \frac{\partial C_{L}}{\partial z}-D_{G} \frac{\partial C_{G}}{\partial z}\right)-R_{T}-R_{U}
$$

\subsection{PARAMETRIZAÇÃO DO SIMULADOR PEARL}

Os dados meteorológicos (temperatura diária máxima e mínima do ar, velocidade do vento, umidade relativa e número de horas de brilho solar) requeridos pelo simulador PEARL para cálculo da evapotranspiração potencial, método de Penman-Monteith, foram obtidos da série temporal de 19 anos (01/01/1980 a 31/12/1998) na Estação Meteorológica da Embrapa Agropecuária Oeste.

Dados relativos às características físico-químicas dos pesticidas foram obtidos na literatura (HORNSBY WAUCHOPE e HERNER, 1996; TOMLIN 2000; PARAÍBA et al., 2003). Os valores de massa molar, solubilidade em água, meia-vida no solo, coeficiente de partição entre o carbono orgânico e a solução do solo para cada princípio ativo avaliado no estudo são mostrados na Tabela 1. O valor do expoente $\mathrm{N}$ de Freundlich (Eq. 9) utilizado para todos os pesticidas foi igual a 0,9. RAO e DAVIDSON (1980) compilaram valores de N para vários pesticidas e verificaram oscilação entre 0,75 e 0,95. O valor de $U$ (Eq. 16) utilizado foi igual a $54 \mathrm{~kJ} \mathrm{~mol}^{-1}$, que corresponde à média encontrada após revisão de 50 experimentos que determinaram esses valores para diversos pesticidas (FOCUS..., 1997). O expoente B (Eq. 17) 
foi considerado igual a 0,7 (BOESTEN e VAN DER LINDEN, 1991), $D_{w}$ (Eq. 12) igual a $4,3 \mathrm{~cm}^{2}$ dia $^{-1}$ (LEISTRA et al., 2002; TIKTAK et al., 2002) e $f_{u}$ igual a 0,5 (TIKTAK et al., 2002).

\section{TABELA 1 - ATRIBUTOS FÍSICO-QUÍMICOS DOS PRINCIPAIS PESTICIDAS UTILIZADOS NA BACIA HIDROGRÁFICA DO RIO DOURADOS, MS}

\begin{tabular}{|c|c|c|c|c|c|}
\hline $\begin{array}{c}\text { Ingrediente } \\
\text { ativo }\end{array}$ & Tipo & $\begin{array}{c}\text { Massa Molar } \\
\left(\mathrm{g} \mathrm{mol}^{-1}\right)\end{array}$ & $\begin{array}{l}\text { Meia-vida } \\
\text { (dias) }\end{array}$ & $\begin{array}{c}\begin{array}{c}\text { Solubilidade } \\
\left(\mathrm{mg} \mathrm{L}^{-1}\right)\end{array} \\
\end{array}$ & $\mathrm{K}_{\mathrm{OC}}\left(\mathbf{L} \mathbf{~ k g}^{-1}\right)$ \\
\hline 2,4-D & Herbicida & 221,0 & 10 & 20031 & 20 \\
\hline Atrazina & Herbicida & 215,7 & 60 & 33 & 107 \\
\hline Bentazona & Herbicida & 240,3 & 20 & 570 & 34 \\
\hline Carbendazim & Fungicida & 191,2 & 20 & 8 & 200 \\
\hline Cipermetrina & Inseticida & 416,3 & 60 & 0,004 & 160000 \\
\hline Clorpirifós & Inseticida & 350,6 & 60 & 1 & 1250 \\
\hline Diclosulam & Herbicida & 406,2 & 50 & 6 & 55 \\
\hline Diquate & Herbicida & 184,2 & 1000 & 700000 & 1000000 \\
\hline Endossulfam & Inseticida & 406,9 & 50 & 0,32 & 12400 \\
\hline Fipronil & Inseticida & 437,2 & 120 & 1900 & 427 \\
\hline $\begin{array}{c}\text { Fluazifope P } \\
\text { butílico }\end{array}$ & Herbicida & 383,4 & 28 & 1 & 40 \\
\hline Flumetsulam & Herbicida & 325,3 & 60 & 100 & 60 \\
\hline Fomesafem & Herbicida & 438,8 & 100 & 50 & 60 \\
\hline Glifosato & Herbicida & 169,1 & 46 & 11600 & 24000 \\
\hline $\begin{array}{l}\text { Haloxifope P } \\
\text { metílico }\end{array}$ & Herbicida & 375,7 & 14 & 9 & 75 \\
\hline Imazaquim & Herbicida & 311,3 & 60 & 120 & 20 \\
\hline Imazetapir & Herbicida & 289,3 & 60 & 1400 & 10 \\
\hline Lactofem & Herbicida & 461,8 & 7 & 1 & 10000 \\
\hline $\begin{array}{l}\text { Lambda } \\
\text { cialotrina }\end{array}$ & Inseticida & 449,9 & 30 & 0,005 & 180000 \\
\hline Metamidofós & Inseticida & 141,1 & 2 & 200000 & 5 \\
\hline Metomil & Inseticida & 162,2 & 45 & 57900 & 72 \\
\hline Monocrotofós & Inseticida & 223,2 & 30 & 1220000 & 1 \\
\hline Nicossulfurom & Herbicida & 410,4 & 26 & 70 & 70 \\
\hline Paraquate & Herbicida & 186,3 & 1000 & 620000 & 10000000 \\
\hline $\begin{array}{l}\text { Parationa } \\
\text { metílica }\end{array}$ & Inseticida & 263,2 & 5 & 55 & 5100 \\
\hline Tiodicarbe & Inseticida & 354,5 & 8 & 35 & 1 \\
\hline Trifluralina & Herbicida & 335,3 & 170 & 0,18 & 6417 \\
\hline
\end{tabular}

Fonte : HORNSBY WAUCHOPE e HERNER (1996); TOMLIN (2000) ; PARAÍBA et al. (2003).

A presença das culturas da soja e do milho safrinha foram consideradas nas simulações, sendo o plantio da soja estabelecido em 01/11, com emergência em 05/11 e colheita em 01/03. Para o milho, o plantio foi estabelecido em 05/03 com emergência em 10/03 e colheita em 10/ 07. Os valores dos índices de área foliar (IAF na Eq. 7) para as culturas de soja e milho safrinha (Tabela 2) foram obtidos em VISSOTTO JÚNIOR (2003) e OLIVEIRA, SANTANA e SILVA (1993), respectivamente, em estudos realizados no Paraná. As alturas de plantas e comprimentos radiculares ao longo do ciclo das culturas de soja e milho safrinha foram estabelecidos com base em observações visuais no campo (Tabela 2). Os fatores de redução ( $\alpha_{\text {red }}$ na Eq. 4) em função do potencial da água no solo (h) para ambas as culturas simuladas foram obtidos em 
WESSELING (1991). O $\alpha_{\text {red }}$ foi igual a zero (sem absorção de água pelas raízes) para $h \geq 0 \mathrm{~cm}$ (solo saturado) e $h \leq-16000 \mathrm{~cm}$. A máxima absorção de água pelas raízes ( $\alpha_{\text {red }}$ igual a 1 ) ocorreu para valores de $\mathrm{h}$ entre -1 e $500 \mathrm{~cm}$ com decréscimo linear estabelecido para 0 intervalo $-1<h<0 \mathrm{~cm}$ e $-16000<h<-500 \mathrm{~cm}$.

\section{TABELA 2 - ÍNDICE DE ÁREA FOLIAR (IAF), COMPRIMENTO DE RAÍZES E ALTURA DE PLANTAS PARA AS CULTURAS DA SOJA E MILHO SAFRINHA CONSIDERADOS NAS SIMULAÇÕES}

\begin{tabular}{cccc}
\hline & \multicolumn{3}{c}{ SOJA } \\
\hline $\begin{array}{c}\text { Dias } \\
\text { acumulados }\end{array}$ & IAF & Altura $(m)$ & Sistema radicular $(m)$ \\
\hline 0 & 0,50 & 0,1 & 0,1 \\
19 & 0,50 & 0,2 & 0,3 \\
47 & 1,50 & 0,4 & 0,6 \\
78 & 3,00 & 0,6 & 0,8 \\
117 & 2,50 & 0,8 & 0,8 \\
120 & 2,00 & 0,8 & 0,8 \\
\hline & & MILHO SAFRINHA & \\
& & & \\
\hline Dias & IAF & Altura (m) & \\
acumulados & & & \\
\hline 0 & 0,18 & 0,1 & 0,1 \\
30 & 0,63 & 0,3 & 0,6 \\
63 & 1,72 & 0,5 & 0,7 \\
93 & 1,29 & 0,8 & 1,0 \\
133 & 2,31 & 1,0 & \\
\hline
\end{tabular}

${ }^{1}$ Dias acumulados a partir da data de plantio.

Fonte: VISSOTTO JÚNIOR (2003); OLIVEIRA, SANTANA e SILVA (1993).

Pelo mapa de solos da BHRD (OLIVEIRA, URCHEI e FIETZ, 2000), os solos predominantes com suas respectivas áreas são o Latossolo Vermelho Distroférrico - LVdf (74,6\%), Latossolo Vermelho Distrófico - LVd (23,2\%), Argissolo Vermelho - PV (1,8\%) e outros $(0,4 \%)$. Coletaram-se amostras de solos nos intervalos de 0-10, 10-20, 20-40, 40-60, 60-100, 100-150 e 150-200 cm de profundidade nos municípios de Dourados (S $22^{\circ} 16^{\prime} 29^{\prime \prime}$ e W $54^{\circ} 48^{\prime}$

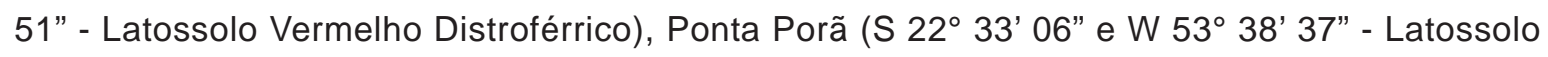
Vermelho Distrófico) e Deodápolis (S $22^{\circ} 14^{\prime} 46^{\prime \prime}$ e W 54 09' 22" - Argissolo Vermelho) para determinação dos atributos químicos e físicos (Tabela 3), além das curvas de retenção de água no solo, condutividade hidráulica em meio poroso saturado, micro, macroporosidade e volume total de poros (Tabela 4). As determinações dos atributos químicos e físicos dos solos foram baseadas nas metodologias descritas em CLAESSEN (1997) e as curvas de retenção de água determinadas em laboratório por meio de secagem em estufa a $105^{\circ} \mathrm{C}$ por $24 \mathrm{~h}$. Para coleta das amostras indeformadas, utilizando-se anéis de 0,055 $\mathrm{m}$ de diâmetro e 0,04 $\mathrm{m}$ de altura, foram abertas trincheiras em cada local de amostragem com $1 \times 1 \mathrm{~m}$ de área e $2 \mathrm{~m}$ de profundidade. As amostras foram saturadas em laboratório até atingir saturação natural e submetidas às tensões de 100, 330, 500, 1000, 3000, 5000, 10000 e $15000 \mathrm{~cm}$ de coluna de água, utilizando- 
se câmara de Richards (CLAESSEN, 1997). Determinou-se a condutividade hidráulica em meio poroso saturado no campo em cada profundidade, utilizando permeâmetro do tipo Guelph, (VIEIRA, 1998). As medições foram realizadas com cargas hidráulicas de 3 e $6 \mathrm{~cm}$ e as leituras no reservatório do permeâmetro em intervalos de 1 minuto. Consideraram-se estáveis três leituras iguais em intervalos de 1 minuto. Os dados das curvas de retenção de água, ou seja, umidades volumétricas em função dos potenciais mátricos foram ajustados ao modelo de VAN GENUCHTEN (1980) utilizando-se o programa RETC (VAN GENUCHETN, LEIJ e YATES, 1991). Verificou-se a qualidade do ajuste ao modelo de VAN GENUCHTEN (1980) com base nos valores do coeficiente de determinação $\left(R^{2}\right)$ e no erro-padrão das estimativas dos coeficientes do modelo (Tabela 4).

\section{TABELA 3 - ATRIBUTOS QUÍMICOS E FÍSICOS EM PERFIS DE $200 \mathrm{~cm}$ DE PROFUNDIDADE DE TRÊS TIPOS DE SOLOS REPRESENTATIVOS DA BACIA HIDROGRÁFICA DO RIO DOURADOS, MS}

\section{Latossolo Vermelho Distroférrico típico textura argilosa - Dourados (MS)}

\begin{tabular}{|c|c|c|c|c|c|}
\hline Prof. (cm) & MO $\left(\mathrm{g} \mathrm{kg}^{-1}\right)$ & Areia $\left(\mathbf{g ~ k g}^{-1}\right)$ & Argila $\left(g_{~ k g} \mathbf{~}^{-1}\right)$ & $\underset{\mathrm{CaCl}_{2}}{\mathrm{pH}}$ & $\rho\left(\mathrm{g} \mathrm{cm}^{-3}\right)$ \\
\hline 0-10 & 33,4 & 245 & 630 & 4,8 & 1,020 \\
\hline $10-20$ & 29,6 & 229 & 663 & 4,4 & 1,114 \\
\hline $20-40$ & 22,7 & 212 & 697 & 4,5 & 1,136 \\
\hline $40-60$ & 16,9 & 195 & 713 & 4,6 & 1,113 \\
\hline $60-100$ & 11,3 & 195 & 713 & 4,6 & 1,104 \\
\hline 100-150 & 6,2 & 195 & 713 & 4,5 & 1,152 \\
\hline $150-200$ & 7,6 & 179 & 713 & 4,4 & 1,140 \\
\hline \multicolumn{6}{|c|}{ Latossolo Vermelho Distrófico típico textura média - Ponta Porã (MS) } \\
\hline Prof. (cm) & MO $\left(\mathrm{g} \mathrm{kg}^{-1}\right)$ & Areia $\left(\mathrm{g} \mathrm{kg}^{-1}\right)$ & Argila $\left(\mathrm{g} \mathrm{kg}^{-1}\right)$ & $\begin{array}{c}\mathrm{pH} \\
\mathrm{CaCl}_{2}\end{array}$ & $\rho\left(\mathrm{g} \mathrm{cm}^{-3}\right)$ \\
\hline 0-10 & 17,5 & 743 & 213 & 4,9 & 1,419 \\
\hline 10-20 & 16,5 & 743 & 230 & 4,9 & 1,509 \\
\hline 20-40 & 13,8 & 726 & 230 & 4,3 & 1,486 \\
\hline $40-60$ & 11,0 & 710 & 247 & 4,2 & 1,461 \\
\hline 60-100 & 6,9 & 693 & 263 & 4,1 & 1,411 \\
\hline $100-150$ & 5,2 & 677 & 263 & 4,1 & 1,456 \\
\hline $150-200$ & 3,8 & 660 & 280 & 4,1 & 1,459 \\
\hline \multicolumn{6}{|c|}{ Argissolo Vermelho Distrófico típico textura média - Deodápolis (MS) } \\
\hline Prof. (cm) & MO $\left(\mathrm{g} \mathrm{kg}^{-1}\right)$ & Areia $\left(\mathrm{g} \mathrm{kg}^{-1}\right)$ & Argila $\left(\mathrm{g} \mathrm{kg}^{-1}\right)$ & $\underset{\mathrm{CaCl}_{2}}{\mathrm{pH}}$ & $\rho\left(\mathrm{g} \mathrm{cm}^{-3}\right)$ \\
\hline 0-10 & 7,4 & 888 & 80 & 4,1 & 1,359 \\
\hline $10-20$ & 6,4 & 869 & 97 & 4,0 & 1,546 \\
\hline $20-40$ & 5,1 & 852 & 111 & 4,0 & 1,532 \\
\hline $40-60$ & 4,7 & 869 & 97 & 4,1 & 1,510 \\
\hline $60-100$ & 5,4 & 888 & 97 & 4,1 & 1,466 \\
\hline $100-150$ & 3,7 & 852 & 111 & 4,0 & 1,475 \\
\hline $150-200$ & 3,7 & 836 & 130 & 4,0 & 1,509 \\
\hline
\end{tabular}




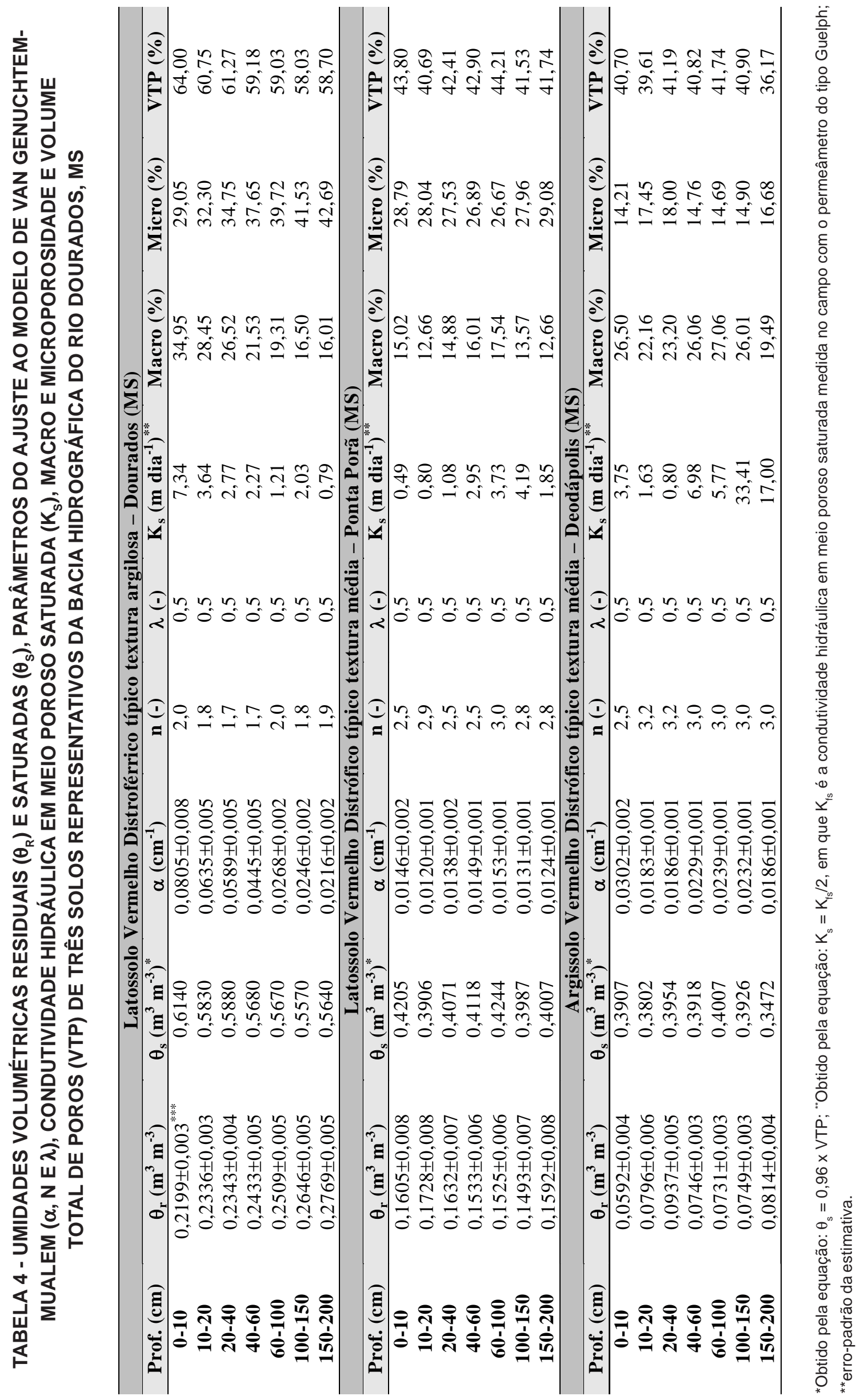


Importante destacar as diferentes texturas dos três solos considerados neste estudo (Tabela 3). Os teores médios de argila para os três solos estudados foram de 69, 25 e 10\% no intervalo de 0 a $200 \mathrm{~cm}$ de profundidade. O teor de matéria orgânica variou de 3,34 a 0,62\% nas diferentes profundidades para o Latossolo Vermelho Distroférrico e de 1,75 a 0,38\% para o Latossolo Vermelho Distrófico. Já para o Argissolo Vermelho, essa variação foi de 0,74 a $0,37 \%$.

O solo com maior volume total de poros foi o Latossolo Vermelho Distroférrico, sendo a variação de 58 a $64 \%$. Todos os solos estudados apresentaram alta macroporosidade, com valores variando de 12 a $34 \%$ nas diferentes profundidades. Os valores de condutividade hidráulica em meio poroso saturado nas diferentes profundidades, estimados com base nas medições com o permeâmetro do tipo Guelph, também se mostraram bastante elevados (URCHEI e FIETZ, 2002).

\subsection{DEFINIÇÃO DOS CENÁRIOS PARA SIMULAÇÕES}

As simulações da lixiviação envolveram 27 pesticidas (Tabela 1) para cada um dos doze municípios e seus diferentes solos (máximo de dois tipos por município dentre os três definidos para estudo). Com base na combinação de pesticidas e municípios foram executadas 560 simulações. Os únicos fatores que influenciaram as simulações foram os tipos de solos e pesticidas, assim dois municípios com o mesmo tipo de solo tiveram os mesmos resultados simulados para determinado pesticida.

Considerou-se a base de dados meteorológicos em todas as simulações (série temporal de 19 anos) e o cultivo de soja e milho safrinha anualmente. As doses dos 27 diferentes pesticidas simulados, bem como as culturas em que foram utilizados e suas respectivas épocas de aplicação são apresentadas na Tabela 5. A profundidade máxima do solo em todas as simulações foi de $12 \mathrm{~m}$ e o nível do lençol freático de $10 \mathrm{~m}$.

\subsection{ESTRATÉGIAS PARA SIMULAÇÃO E CRITÉRIOS PARA ANÁLISE DE RISCO}

Foram considerados os seguintes resultados das simulações para a análise de risco: (i) profundidade máxima de lixiviação $\left(Z_{\max }\right)$ e (ii) concentração dos pesticidas na fase líquida do solo $\left(C_{L}\right)$ a 2, 5 e $10 \mathrm{~m}$ de profundidade.

Para o cálculo de $Z_{\max }$ foram computadas apenas concentrações superiores a $10^{-7} \mathrm{~kg} \mathrm{~m}^{-3}$, ou seja, $0,1 \mu \mathrm{g} \mathrm{L}^{-1}$. Tal concentração é inferior aos valores máximos permitidos para maioria dos pesticidas em água potável, estabelecidos pela Portaria 518 do Ministério da Saúde (BRASIL, 2004).

O critério utilizado na análise de risco baseou-se na medida de posição relativa denominada de percentil (TIKTAK et al., 2006). Para cada simulação (envolvendo período de 19 anos) calculou-se a $C_{L}$ a 2, 5 e $10 \mathrm{~m}$ de profundidade referente a $80 \%$ percentil $\left(C_{L-80}\right)$. Em termos práticos, o valor de $\mathrm{C}_{\mathrm{L}-80}$ significa que $80 \%$ dos valores simulados de $\mathrm{C}_{\mathrm{L}}$ em determinada profundidade durante os 19 anos estão abaixo de $\mathrm{C}_{\mathrm{L}-80^{\circ}}$.

Os valores de $\mathrm{C}_{\mathrm{L}-80}$ foram comparados com os valores máximos permitidos de resíduos de pesticidas em água potável, estabelecidos pelo Ministério da Saúde por meio da Portaria 518 (BRASIL, 2004). 


\section{TABELA 5 - CRONOGRAMA DE APLICAÇÃO, CULTURAS E DOSES DOS PESTICIDAS CONSIDERADOS NAS SIMULAÇÕES DA BACIA HIDROGRÁFICA DO RIO DOURADOS, MS}

\begin{tabular}{|c|c|c|c|}
\hline Princípio ativo & Cultura & Dose i.a. $\left(\mathrm{kg} \mathrm{ha}^{-1}\right)$ & Data de aplicação \\
\hline \multirow{2}{*}{$2,4-\mathrm{D}$} & Soja & 0,81 & $15 / 10$ \\
\hline & Milho & 0,81 & $01 / 03$ \\
\hline Atrazina & Milho & 1,5 & $15 / 03$ \\
\hline \multirow{2}{*}{ Bentazona } & Soja & 0,72 & $20 / 11$ \\
\hline & Milho & 0,72 & $20 / 03$ \\
\hline Carbendazim & Soja & 0,25 & $30 / 01$ \\
\hline Cipermetrina & Soja & 0,05 & $15 / 11$ \\
\hline \multirow{2}{*}{ Clorpirifós } & Soja & 0,12 & $15 / 11$ \\
\hline & Milho & 0,12 & $10 / 03$ \\
\hline Diclosulam & Soja & 0,035 & $01 / 11$ \\
\hline \multirow{2}{*}{ Diquate } & Soja & 0,2 & $15 / 10$ \\
\hline & Milho & 0,2 & $25 / 02$ \\
\hline \multirow{2}{*}{ Endossulfam } & \multirow{2}{*}{ Soja } & 0,44 (lagarta) & 01/12 (lagarta) \\
\hline & & 0,11 (percevejo) & 15/01 (percevejo) \\
\hline Fipronil & Soja & 0,006 & $01 / 12$ \\
\hline Fluazifope P butílico & Soja & 0,19 & $20 / 11$ \\
\hline Flumetsulam & Soja & 0,14 & $01 / 11$ \\
\hline Fomesafem & Soja & 0,25 & $20 / 11$ \\
\hline \multirow{5}{*}{ G lifo sato } & \multirow[t]{2}{*}{ Soja Convencional } & 1,92 & $15 / 10$ \\
\hline & & 0,72 & $01 / 11$ \\
\hline & \multirow[t]{2}{*}{ Soja Transgênica } & 1,92 & $\begin{array}{l}15 / 10 \\
01 / 11\end{array}$ \\
\hline & & 0,96 & $15 / 11$ \\
\hline & Milho & 1,44 & $01 / 03$ \\
\hline Haloxifope P metílico & Soja & 0,06 & $25 / 11$ \\
\hline Imazaquim & Soja & 0,15 & $01 / 11$ \\
\hline Imazetapir & Soja & 0,1 & $20 / 11$ \\
\hline Lactofem & Soja & 0,18 & $20 / 11$ \\
\hline Lambda cialotrina & Milho & 0,004 & $15 / 03$ \\
\hline \multirow{2}{*}{ Metamido fós } & Soja & 0,42 & $15 / 11 ; 15 / 12 ; 15 / 01$ \\
\hline & Milho & 0,42 & $25 / 02 ; 10 / 03$ \\
\hline \multirow{2}{*}{ Metomil } & Soja & 0,11 & $15 / 01$ \\
\hline & Milho & 0,13 & $15 / 03$ \\
\hline Monocrotofós & Soja & 0,15 & $30 / 11 ; 30 / 12$ \\
\hline Nicossulfuron & Milho & 0,04 & $15 / 03$ \\
\hline \multirow{2}{*}{ Paraquate } & Soja & 0,3 & $15 / 10$ \\
\hline & Milho & 0,3 & $01 / 03$ \\
\hline \multirow{2}{*}{ Parationa metílica } & Soja & 0,48 & $15 / 11 ; 15 / 12 ; 15 / 01$ \\
\hline & Milho & 0,48 & $25 / 02 ; 10 / 03$ \\
\hline \multirow{2}{*}{ Tiodicarbe } & Soja & 0,08 & $15 / 11 ; 30 / 11$ \\
\hline & Milho & 0,08 & $15 / 03$ \\
\hline Trifluralina & Soja & 0,89 & $01 / 11$ \\
\hline
\end{tabular}

\section{RESULTADOS E DISCUSSÃO}

O princípio ativo mais usado, considerando todos os municípios componentes da BHRD e culturas, foi o glifosato com 14,8\% (Figura 1A). Em seguida, os mais usados foram o 2,4-D (5,6\%), fipronil $(5,4 \%)$, metamidofós $(5,2 \%)$, imazaquim $(3,7 \%)$, parationa metílica $(3,6 \%)$, trifluralina $(3,5 \%)$, atrazina $(3,2 \%)$, cipermetrina $(2,8 \%)$, clorpirifós $(2,6 \%)$, monocrotofós $(2,4 \%)$, tiodicarbe $(2,4 \%)$, carbendazim $(2,3 \%)$ e paraquate $(2,2 \%)$. Os princípios ativos haloxifope $\mathrm{P}$ metílico, endossulfan, 
lufenuron, nicossulfurom, lambda cialotrina, diclosulam, flumetsulam e metomil apresentaram freqüência de uso inferior a $1 \%$. As culturas que mais consumiram pesticidas foram a soja $(62,7 \%)$, o milho $(21,9 \%)$, as pastagens $(7,5 \%)$, o trigo $(3,2 \%)$ e o feijão $(2,2 \%)$. As culturas de arroz, algodão e tomate evidenciaram consumo de pesticidas inferior a 1\% (Figura 1B). $\mathrm{O}$ maior consumo de pesticidas pelas culturas da soja e milho ocorreu devido seu predomínio na BHRD. A área colhida com soja no ano de 2002, considerando os 12 municípios componentes da BHRD, foi de 382.635 ha e a de milho de 164.792 ha. Essas áreas representaram 62,2 e $26,8 \%$, respectivamente, de toda área plantada na BHRD (INDICADORES..., 2004). Os municípios que mais utilizaram pesticidas foram Dourados (32,1\%), Caarapó (18,6\%), Ponta Porã (16,3\%), Itaporã (12,6\%), Laguna Carapã (7,5\%), Fátima do Sul (5,5\%), Deodápolis (2,7\%), Vicentina (2,2\%) e Antônio João (1,8\%) (Figura 1C). Os municípios de Glória de Dourados, Jateí e Ivinhema consumiram menos de $1 \%$ do total de pesticidas comercializados na BHRD. As classes de pesticidas mais usadas foram os herbicidas $(52,6 \%)$, inseticidas $(37,5 \%)$ e fungicidas (8,2\%) (Figura 1D). Os resultados acima mostram que de maneira geral, a avaliação do potencial de contaminação dos recursos hídricos na BHRD deve priorizar os 22 pesticidas mostrados na Figura 1A, bem como os municípios de Dourados, Caarapó, Ponta Porã, Itaporã e Laguna Carapã que consumiram aproximadamente $80 \%$ do total de pesticidas comercializados na BHRD.

Observou-se grande variação com relação aos valores de profundidades máximas $\left(Z_{\max }\right)$ para os diferentes pesticidas, bem como em relação aos tipos de solos para o mesmo pesticida (Tabela 6). A $Z_{\text {max }}$ da cipermetrina foi de $0 \mathrm{~m}$ para todos os solos (não foram encontradas concentrações superiores a $0,1 \mu \mathrm{g} \mathrm{L}^{-1}$ abaixo da superfície do solo durante os 19 anos de simulação), enquanto que para o monocrotofós o valor de $Z_{\max }$ variou de $2 \mathrm{~m}$ no solo LVdf até $10 \mathrm{~m}$ para os solos LVd e PV. Os pesticidas cipermetrina, carbendazim, paraquate, lambda cialotrina, lactofem e diquate apresentaram valores de $Z_{\max }$ iguais a $0 \mathrm{~m}$ nos três tipos de solos estudados, mostrando baixo potencial de lixiviação e de contaminação de água subterrânea. Os pesticidas glifosato, parationa metílica, trifluralina e endossulfam apresentaram valores de $Z_{\max }$ inferiores a 0,2 $\mathrm{m}$, evidenciando também baixo potencial de lixiviação e contaminação de água subterrânea Deve-se ressaltar que para esses últimos pesticidas, os maiores valores de $Z_{\max }$ ocorreram no solo $\mathrm{PV}$. Isso demonstra a influência de sua alta condutividade hidráulica, alta macroporosidade e baixos teores de matéria orgânica (Tabelas 3 e 4), que favorecem alto fluxo de água na matriz do solo e baixa retenção dos pesticidas. Nos municípios da BHRD a água subterrânea ocorre abaixo de PV, geralmente mais vulnerável à contaminação por pesticidas quando comparado aos solos LVdf e LVd. Importante ressaltar que outros fatores devem ser considerados na avaliação de vulnerabilidade e não apenas o tipo de solo. Embora os pesticidas cipermetrina, carbendazim, paraquate, lambda cialotrina, lactofem, diquate, glifosato, parationa metílica, trifluralina e endossulfam apresentem baixo potencial de lixiviação e contaminação de águas subterrâneas deve-se lembrar que são pesticidas com alta adsorção às partículas do solo (altos valores de $\mathrm{K}_{\mathrm{oc}}$ ). Portanto, podem ser transportados mediante escoamento superficial após formação de enxurradas, contaminando águas superficiais (lagos e rios, entre outros). Os pesticidas com maiores potenciais de contaminação da água subterrânea foram bentazona, imazetapir, fomesafem, 2,4-D, metamidofós, imazaquim, tiodicarbe e monocrotofós. Todos esses pesticidas apresentaram valores de $Z_{\text {max }}$ iguais a $10 \mathrm{~m}$ em pelo menos um tipo de solo (Tabela 6). Dentre esses, monocrotofós, imazetapir, fomesafem e imazaquim apresentaram valores de $Z_{\max }$ iguais a $10 \mathrm{~m}$ nos solos PV e LVd. Os pesticidas fipronil, atrazina, clorpirifós, haloxifope P metílico, nicossulfurom, diclosulam, flumetsulam, metomil e fluazifope $P$ butílico com valores máximos de $Z_{\max }$ a $5 \mathrm{~m}$ foram classificados como pesticidas com potenciais intermediários de contaminação (considerando nível do lençol freático de $10 \mathrm{~m}$ ). 
FIGURA 1 - PRINCÍPIOS ATIVOS MAIS USADOS (A), CULTURAS (B), MUNICÍPIOS QUE MAIS UTILIZARAM PESTICIDAS (C) E CLASSES DE PESTICIDAS MAIS USADAS (D)

NA BACIA HIDROGRÁFICA DO RIO DOURADOS, MS, 2002
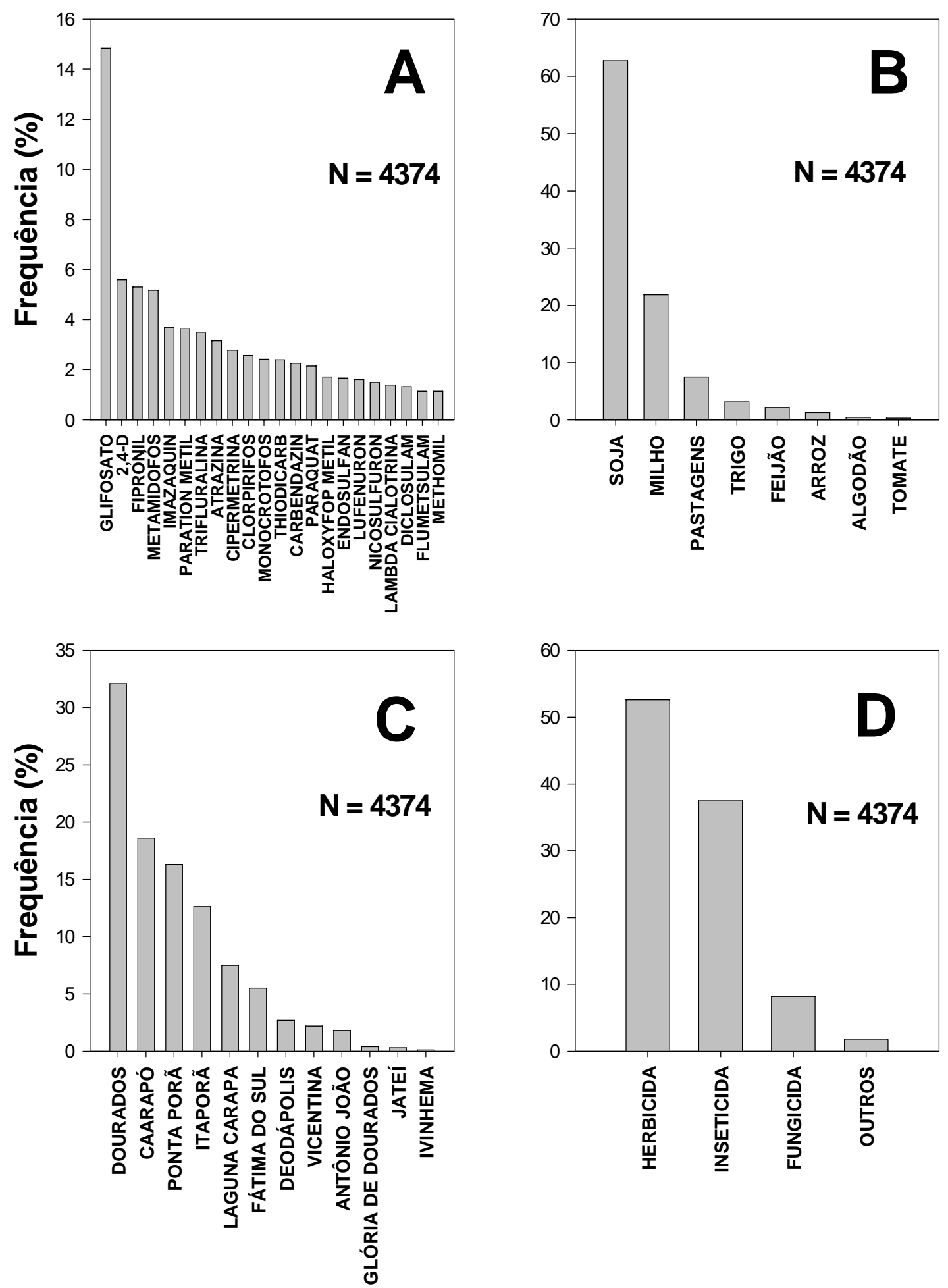

Gráficos com escalas diferentes no eixo y.

O valor de n refere-se ao número de receituários agronômicos. 


\section{TABELA 6 - PROFUNDIDADES MÁXIMAS DE LIXIVIAÇÃO $\left(Z_{\text {MAX }}\right)$ PARA OS DIFERENTES PESTICIDAS UTILIZADOS NA BACIA HIDROGRÁFICA DO RIO DOURADOS, MS, CONSIDERANDO OS TRÊS TIPOS DE SOLOS}

\begin{tabular}{|c|c|c|c|}
\hline \multirow{2}{*}{ Pesticidas } & \multicolumn{3}{|c|}{$\mathrm{Z}_{\max }(\mathrm{m})$} \\
\hline & LVdf ${ }^{*}$ & $\mathbf{L V d}^{* *}$ & $\mathbf{P V}^{* * *}$ \\
\hline $2,4-\mathrm{D}$ & 1 & 1 & 10 \\
\hline Atrazina & 0,75 & 1 & 5 \\
\hline Bentazona & 1 & 2 & 10 \\
\hline Carbendazim & $0^{* * * *}$ & 0 & 0 \\
\hline Cipermetrina & 0 & 0 & 0 \\
\hline Clorpirifós & 0,05 & 0,1 & 0,5 \\
\hline Diclosulam & 0,5 & 0,5 & 5 \\
\hline Diquate & 0 & 0 & 0 \\
\hline Endossulfam & 0 & 0,05 & 0,1 \\
\hline Fipronil & 0,05 & 0,05 & 0,75 \\
\hline Fluazifope P butílico & 0,74 & 1 & 5 \\
\hline Flumetsulam & 0,74 & 1 & 5 \\
\hline Fomesafem & 2 & 10 & 10 \\
\hline Glifosato (soja convencional) & 0 & 0 & 0,1 \\
\hline Glifosato (soja transgênica) & 0 & 0 & 0,1 \\
\hline Haloxifope P metílico & 0,2 & 0,3 & 2 \\
\hline Imazaquim & 1 & 10 & 10 \\
\hline Imazetapir & 2 & 10 & 10 \\
\hline Lactofem & 0 & 0 & 0 \\
\hline Lambda cialotrina & 0 & 0 & 0 \\
\hline Metamidofós & 1 & 1 & 10 \\
\hline Metomil & 0,74 & 1 & 5 \\
\hline Monocrotofós & 2 & 10 & 10 \\
\hline Nicossulfuron & 0,4 & 0,5 & 1 \\
\hline Paraquate & 0 & 0 & 0 \\
\hline Parationa metílica & 0 & 0 & 0,2 \\
\hline Tiodicarbe & 1 & 2 & 10 \\
\hline Trifluralina & 0,05 & 0,05 & 0,2 \\
\hline
\end{tabular}

" LVd = Latossolo Vermelho distrófico; ** LVdf = Latossolo Vermelho Distroférrico; *** PV = Argissolo Vermelho.

Valores iguais a zero significam que não foram encontradas concentrações superiores a $0,1 \mu \mathrm{g} \mathrm{L}^{-1} \mathrm{em}$ nenhuma profundidade durante os 19 anos de simulação.

Os valores de $Z_{\max }$ indicam apenas as profundidades máximas de lixiviação estimadas para os diferentes pesticidas, sem qualquer referência às concentrações esperadas (importante fator da análise de risco). Os valores simulados de $C_{\llcorner}$a 2, 5 e $10 \mathrm{~m}$ de profundidade referentes a $80 \%$ percentil $\left(\mathrm{C}_{\mathrm{L}-80}\right)$ são mostrados na Tabela 7. Para esse cálculo, foram considerados apenas os pesticidas que apresentaram valores de $Z_{\max }$ iguais ou superiores a $2 \mathrm{~m}$. Na profundidade de $2 \mathrm{~m}$, os maiores valores de $\mathrm{C}_{\mathrm{L}-80}$ ocorreram para os pesticidas monocrotofós $\left(5,91 \mu \mathrm{g} \mathrm{L}^{-1}\right)$, imazetapir $\left(4,12 \mu \mathrm{g} \mathrm{L}^{-1}\right)$ e fomesafem $\left(4,10 \mu \mathrm{g} \mathrm{L}^{-1}\right)$ no solo PV. A Portaria 518 de 25 de março de 2004 (BRASIL, 2004) não estabelece valores máximos de resíduos para esses pesticidas em água potável. Considerado o valor máximo permitido para resíduos de pesticidas em água potável estabelecido pela Comunidade Européia $\left(0,1 \mu \mathrm{g} \mathrm{L}^{-1}\right)$ observa-se que os valores de $\mathrm{C}_{\mathrm{L}-80}$ a $2 \mathrm{~m}$ de profundidade 
para o monocrotofós, imazetapir e fomesafem ficaram bem acima do permitido. Dentre os pesticidas mostrados na Tabela 7, a Portaria 518 estabelece valores máximos de resíduos em água potável apenas para o 2,4-D (30 $\left.\mathrm{g} \mathrm{L} \mathrm{L}^{-1}\right)$, atrazina $\left(2 \mu \mathrm{g} \mathrm{L}^{-1}\right)$ e bentazona $\left(300 \mu \mathrm{g} \mathrm{L^{-1 }}\right)$. Os valores de $\mathrm{C}_{\mathrm{L}-80}$ desses três pesticidas para todas as profundidades e solos não atingiram os valores máximos permitidos pela legislação brasileira, mas a atrazina $\left(0,13 \mu \mathrm{g} \mathrm{L}^{-1}\right)$ e a bentazona $\left(0,51 \mu \mathrm{g} \mathrm{L}^{-1}\right)$ a $2 \mathrm{~m}$ de profundidade no solo PV ultrapassaram o valor máximo de $0,1 \mu \mathrm{g} \mathrm{L}^{-1}$ estabelecido pela Comunidade Européia (alto potencial de contaminação de água subterrânea para esse solo). Com relação aos valores de $\mathrm{C}_{\mathrm{L}-80}$ para 5 e $10 \mathrm{~m}$ de profundidade, os pesticidas fomesafem, imazaquim, imazetapir e monocrotofós apresentaram os maiores valores (Tabela 7). Considerando os valores de $\mathrm{C}_{\mathrm{L}-80}$ em todas as profundidades e tipos de solos, bem como o limite de 0,1 $\mu \mathrm{g} \mathrm{L}^{-1}$ para os resíduos de pesticidas em água potável, os pesticidas com maior potencial de contaminação da água subterrânea são: atrazina, bentazona, fomesafem, imazaquim, imazetapir, metomil e monocrotofós.

\section{TABELA 7 - VALORES SIMULADOS (80\% PERCENTIL) DAS CONCENTRAÇÕES DOS PESTICIDAS NA FASE LÍQUIDA DO SOLO A 2, 5 E $10 \mathrm{~m}$ DE PROFUNDIDADE $\left(\mathrm{C}_{\mathrm{L}-80}\right)$}

\begin{tabular}{|c|c|c|c|c|}
\hline \multirow{2}{*}{ Pesticida } & \multirow{2}{*}{ Solo* } & \multicolumn{3}{|c|}{$C_{L-80}\left(\mu g^{-1}\right)$} \\
\hline & & $2 \mathrm{~m}$ & $5 \mathrm{~m}$ & $10 \mathrm{~m}$ \\
\hline $2,4-D$ & PV & 0,003 & 0 & 0 \\
\hline Atrazina & PV & 0,126 & 0 & 0 \\
\hline \multirow{2}{*}{ Bentazona } & $\mathrm{LVd}$ & 0,020 & 0,026 & 0,011 \\
\hline & PV & 0,507 & 0 & 0 \\
\hline Diclosulam & $\mathrm{PV}$ & 0,005 & 0 & 0 \\
\hline Fluazifope P butílico & PV & 0,069 & 0 & 0 \\
\hline Flumetsulam & $\mathrm{PV}$ & 0,083 & 0 & 0 \\
\hline \multirow{3}{*}{ Fomesafem } & $\mathrm{LVd}$ & 0,871 & 0,718 & 0,680 \\
\hline & LVdf & 0,023 & 0 & 0 \\
\hline & PV & 4,098 & 0,085 & 0 \\
\hline Haloxifope P metílico & $\mathrm{PV}$ & 0 & 0 & 0 \\
\hline \multirow{2}{*}{ Imazaquim } & $\mathrm{LVd}$ & 0,297 & 0,257 & 0,242 \\
\hline & PV & 1,428 & 0,028 & 0 \\
\hline \multirow{2}{*}{ Imazetapir } & $\mathrm{LVd}$ & 1,200 & 0,984 & 0,862 \\
\hline & PV & 4,121 & 0,592 & 0,012 \\
\hline Metamidofós & PV & 0 & 0 & 0 \\
\hline Metomil & $\mathrm{PV}$ & 0,129 & 0 & 0 \\
\hline \multirow{3}{*}{ Monocrotofós } & $\mathrm{LVd}$ & 1,162 & 0,918 & 0,872 \\
\hline & LVdf & 0,095 & 0 & 0 \\
\hline & PV & 5,909 & 0,332 & 0,006 \\
\hline \multirow{2}{*}{ Tiodicarbe } & $\mathrm{LVd}$ & 0 & 0,001 & 0,001 \\
\hline & $\mathrm{PV}$ & 0,004 & 0 & 0 \\
\hline
\end{tabular}

${ }^{*}$ LVd = Latossolo Vermelho distrófico; LVdf = Latossolo Vermelho Distroférrico; PV = Argissolo Vermelho.

Alguns dos pesticidas estudados são ionizáveis, ou seja, adquirem carga quando em solução aquosa (por exemplo, o 2,4-D, imazaquim, atrazina, carbendazim, nicossulfurom, diclosulam, flumetsulam, bentazona, imazetapir e fomesafem). Pesticidas ionizáveis comportam-se de maneira 
diferente das formas neutras ou não-ionizáveis (NICHOLLS e EVANS, 1991). Comumente, a maioria dos solos apresenta balanço de cargas negativo (BRADY, 1989). Com isso, pesticidas de caráter ácido apresentam alto potencial de lixiviação devido sua baixa retenção no solo. Em solos oxídicos, como é o caso dos solos na BHRD, o horizonte B pode em alguns casos apresentar balanço de cargas positivo (SPADOTTO e HORSNBY, 2003) e, conseqüentemente, retardar a lixiviação de pesticidas de caráter ácido como, por exemplo, imazaquim, bentazona e atrazina. Outro processo importante a ser considerado durante a avaliação do potencial de lixiviação de pesticidas é o transporte preferencial, que ocorre quando o pesticida se move rapidamente no solo juntamente com a água de infiltração através dos macroporos e com pouca interação com as partículas do solo responsáveis pela retenção (FLURY, 1996; LARSSON e JARVIS, 1999; ZEHE e FLÜHLER, 2001; SCORZA JÚNIOR et al., 2004). O transporte preferencial eleva o potencial de contaminação de águas subterrâneas, já que devido sua rápida lixiviação não há tempo necessário para interação com a camada superficial do solo em que os processos de retenção e degradação são mais intensos. Observa-se que para os três solos da BHRD considerados nesse estudo, os valores de macroporosidade variaram de 12,66 a 34,95\% nas diversas profundidades (Tabela 4). Esses valores são elevados e podem propiciar a ocorrência do transporte preferencial de pesticidas nos solos da BHRD, aumentando o potencial de contaminação da água subterrânea.

\section{CONCLUSÃo}

O pesticida mais usado na BHRD no ano de 2002 foi o glifosato, seguido em ordem decrescente pelo 2,4-D, fipronil, metamidofós, imazaquim, parationa metílica, trifluralina, atrazina, cipermetrina, clorpirifós, monocrotofós, tiodicarbe, carbendazim e paraquate. As culturas que mais consumiram pesticidas em ordem decrescente de uso, no ano de 2002, foram a soja, o milho, as pastagens, o trigo e o feijão, enquanto os municípios foram Dourados, Caarapó, Ponta Porã e Itaporã. Os pesticidas que apresentaram os maiores potenciais de lixiviação e contaminação da água subterrânea na BHRD foram o bentazona, imazetapir, fomesafem, 2,4-D, metamidofós, imazaquim, tiodicarbe e monocrotofós.

\section{ABSTRACT \\ THE POTENTIAL OF CONTAMINATION OF GROUNDWATER BY PESTICIDES IN DOURADOS RIVER WATERSHED, MS - BRAZIL}

This work had the following aims: (i) to create a database with information about the use of pesticides in Dourados river watershed; (ii) to simulate the leaching of main pesticides applied at Dourados river watershed by using PEARL; (iii) to establish a ranking considering the main pesticides and their potential to contaminate groundwater. Database contained 4,374 agronomic prescriptions that were prescribed in 2002. PEARL input data were obtained experimentaly or from the literature. Simulations were carried out considering a period of 19 years to obtain soil concentrations in liquid phase at 2, 5 and $10 \mathrm{~m}$ depth and the maximum leaching depth. The most used pesticides on the watershed were glyphosate followed by 2,4-D, fipronil, methamidophos, imazaquin, parathion-methyl, trifluralin, and atrazine. Simulations revealed that pesticides with the highest potential of groundwater contamination were bentazon, imazethapyr, fomesafen, 2,4-D, methamidophos, imazaquin, thiodicarb, and monocrotophos.

KEY-WORDS: ENVIRONMENTAL CONTAMINATION; PESTICIDES; DOURADOS RIVER; PEARL, LEACHING.

\section{REFERÊNCIAS}

1 BOESTEN, J.J.T.I.; VAN DER LINDEN, A.M.A. Modeling the influence of sorption and transformation on pesticide leaching and persistence. Journal of Environmental Quality, v.20, p.425-435, 1991. 
2 BOTTONI, P.; FUNARI, E. Criteria for evaluating the impact of pesticides on groundwater quality. The Science of the Total Environment, v.123/124, p.581-590, 1992.

3 BRADY, N.C. Natureza e propriedade dos solos. 7. ed. Rio de Janeiro: Freitas Bastos, 1989. 878 p.

4 BRASIL. Ministério da Saúde. Portaria n 518 de 25 de março de 2004. Estabelece os procedimentos e responsabilidades relativos ao controle e vigilância da qualidade da água para consumo humano e seu padrão de potabilidade. Diário Oficial [da] República Federativa do Brasil, Brasília, DF, 26 mar. 2004.

5 CARTER, A. How pesticides get into water - and a proposed reduction measures. Pesticide Outlook, v.11, p.149-156, 2000.

6 CHAIN, A.; VALARINI, P.J.; OLIVEIRA, D.A.; MORSOLETO, R.V.; PIO, L.C. Avaliação de perdas de pulverização em culturas de feijão e tomate. Jaguariúna: Embrapa Meio Ambiente, 1999. 29 p. (Embrapa Meio Ambiente. Boletim de Pesquisa, 2).

7 CLAESSEN, M.E.C. (Org.). Manual de métodos de análise de solo. 2. ed. ver. atual. Rio de Janeiro: Embrapa-CNPS, 1997. 212 p. (Embrapa-CNPS. Documentos, 1).

8 COHEN, S.Z.; WAUCHOPE, R.D.; KLEIN, A.W.; EADSFORTH, C.V.; GRANEY, R. Offsite transport of pesticides in water mathematical models of pesticide leaching and runoff. International Union of Pure and Applied Chemistry, v.67, n.12, p.2109-2148, 1995.

9 DOMAGALSKI, J.L.; DUBROVSKY, N.M. Pesticide residues in ground water of the San Joaquin Valley, California. Journal of Hydrology, v.130, p.299-338, 1992.

10 FEDDES, R.A.; KOWALIK, P.J.; ZARADNY, H. Simulation of field water use and crop yield. Wageningen: PUDOC, 1978. $189 \mathrm{p}$

11 FLURY, M. Experimental evidence of transport of pesticides through field soils - a review. Journal of Environmental Quality, v.25, p.25-45, 1996.

12 FOCUS SOIL MODELLING WORKGROUP. Soil persistence models and EU registration. Brussels: Commission of the European Communities, 1997. 77 p. (Doc. 7617/VI/96).

13 GUSTAFSON, D.I. Groundwater ubiquity score: a simple method for assessing pesticide leachability. Environmental Toxicology and Chemistry, v.8, p.339-357, 1989.

14 HORNSBY, A.G.; WAUCHOPE, R.D.; HERNER, A.E. Pesticide properties in the environment. New York: SpringerVerlag, 1996. $227 \mathrm{p}$.

15 INDICADORES e estatísticas: indicadores básicos dos municípios - 2004. Campo Grande, MS: Secretaria de Estado de Planejamento e de Ciência e Tecnologia, 2004. Disponível em: http://www.seplanct.ms.gov.br. Acesso em: 14 dez. 2006.

16 LARSBO, M.; JARVIS, N.J. MACRO 5.0. A model of water flow and solute transport in macroporous soil. Technical description. Uppsala, Sweden: Swedish University of Agricultural Sciences, 2003. 48 p.

17 LARSSON, M.H.; JARVIS, N.J. Evaluation of a dual-porosity model to predict field-scale solute transport in a macroporous soil. Journal of Hydrology, v.215, p.153-171. 1999.

18 LAVORENTI, A.; PRATA, F.; REGITANO, J.B. Comportamento de pesticidas em solos: fundamentos. Tópicos em Ciência do Solo, v.3, p.291-334, 2003.

19 LEISTRA, M.; VAN DER LINDEN, A.M.A.; BOESTEN, J.J.T.I.; TIKTAK, A.; VAN DEN BERG, F. PEARL model for pesticide behaviour and emissions in soil-plant systems: description of the processes in FOCUS PEARL v. 1.1.1. Wageningen: Alterra, 2002. 117 p. (Alterra Report, 13).

20 LOURENCETTI, C.; SPADOTTO, C.A.; SANTIAGO-SILVA, M.; RIBEIRO, M.L. Avaliação do potencial de contaminação de águas subterrâneas por pesticidas: comparação entre métodos de previsão de lixiviação. Pesticidas: revista de ecotoxicologia e meio ambiente, v.15, p.1-14, 2005.

21 MALONE, R.W.; AHUJA, L.R.; MA, L.; WAUCHOPE, R.D.; MA, Q.; ROJAS, K.W. Application of the root zone water quality model (RZWQM) to pesticide fate and transport: an overview. Pest Management Science, v.60, p.205-221, 2004.

22 MONTEITH, J.L. Evaporation and environment. In: SYMPOSIA OF THE SOCIETY FOR EXPERIMENTAL BIOLOGY, 19., 1965, New York. The state and movement of water in living organisms. New York: Academic Press, 1965. p.205234.

23 MUALEM, Y. A new model for predicting the hydraulic conductivity of unsaturated porous media. Water Resources Research, v.12, p.513-522, 1976.

24 NICHOLLS, P.H.; EVANS, A.A. Sorption of ionisable organic compounds by field soils. Part 1: acids. Pesticide Science, v.33, p.319-330, 1991. 
25 OLIVEIRA, F.A.; SANTANA, E.; SILVA, J.J. Evapotranspiração e desenvolvimento radicular do milho irrigado. Pesquisa Agropecuária Brasileira, v.28, p.1407-1415, 1993.

26 OLIVEIRA, H.; URCHEI, M.A.; FIETZ, C.R. Aspectos físicos e socioeconômicos da Bacia Hidrográfica do Rio Ivinhema. Dourados: Embrapa Agropecuária Oeste, 2000. 52 p. (Embrapa Agropecuária Oeste. Documentos, 25).

27 PARAÍBA, L.C.; CERDEIRA, A.L.; SILVA, E.F.; MARTINS, J.S.; COUTINHO, H.L.C. Evaluation of soil temperature effect on herbicide leaching potential into groundwater in the Brazilian Cerrado. Chemosphere, v.53, p.1087-1095, 2003.

28 PARAÍBA, L.C.; SPADOTTO, C.A. Soil temperature effect in calculating attenuation and retardation factors. Chemosphere, v.48, p.905-912, 2002.

29 PESSOA, M.C.P.Y.; LUCHIARI JÚNIOR, A.; FERNANDES, E.N.; LIMA, M.A. Principais modelos matemáticos e simuladores utilizados para análise de impactos das atividades agrícolas. Jaguariúna: Embrapa-CNPMA, 1997. 83 p. (Embrapa-CNPMA. Documentos, 8).

30 RAO, P.S.C.; DAVIDSON, J.M. Estimation of pesticide retention and transformation parameters required in non-point source pollution models. In: OVERCASH, M.R.; DAVIDSON, J.M. (Ed.). Environmental impact of nonpoint source pollution. Ann Arbor: Ann Arbor Scientific, 1980. p.23-67.

31 RAO, P.S.C.; HORNSBY, A.G.; JESSUP, R.E. Indices for ranking the potential for pesticide contamination of groundwater. Soil and Crop Science Society of Florida, v.44, p.1-8, 1985.

32 SCORZA JÚNIOR, R.P.; SMELT, J.H.; BOESTEN, J.J.T.I.; HENDRIKS, R.F.A.; VAN DER ZEE, S.E.A.T.M. Preferential flow of bromide, bentazon, and imidacloprid in a Dutch clay soil. Journal of Environmental Quality, v.33, p.1473-1486, 2004.

33 SPADOTTO, C.A. Screening method for assessing pesticide leaching potential. Pesticidas: revista de ecotoxicologia e meio ambiente, v.12, p.69-78, 2002.

34 SPADOTTO, C.A.; HORNSBY, A.G. Soil sorption of acidic pesticides: modeling pH effects. Journal of Environmental Quality, v.32, p.949-956, 2003

35 TIKTAK, A.; BOESTEN, J.J.T.I.; VAN DER LINDEN, A.M.A.; VANCLOOSTER, M. Mapping ground water vulnerability to pesticide leaching with a process-based metamodel of EuroPEARL. Journal of Environmental Quality, v.35, p.12131226, 2006

36 TIKTAK, A.; VAN DER BERG, F.; BOESTEN, J.J.T.I.; VAN KRAALINGEN, D.; LEISTRA, M.; VAN DER LINDEN, A.M.A. Manual of FOCUS PEARL version 1.1.1. Bilthoven: RIVM/ALTERRA, 2002. 144 p. (RIVM Report 711401008).

37 TOMLIN, C.D.S. (ed.) The pesticide manual. 12 ${ }^{\text {th }}$. Ed. Farnham: British Crop Protection Council, 2000.1250 p.

38 URCHEI, M.A.; FIETZ, C.R. Infiltração de água em um Latossolo Roxo muito argiloso em dois sistemas de manejo. Irriga, v.7, p.1-9, 2002.

39 VAN DAM, J.C.; HUYGEN, J.; WESSELING, J.G.; FEDDES, R.A.; KABAT, P.; VAN WALSUM, P.E.V.; GROENENDIJK, P.; VAN DIEPEN, C.A. Theory of SWAP version 2.0: simulation of water flow, solute transport and plant growth in the soil-water-atmosphere-plant environment. Wageningen: Wageningen Agricultural University, 1997. 167 p. (Wageningen Agricultural University, Report 71).

40 VAN GENUCHTEN, M.Th. A closed form equation for predicting the hydraulic conductivity of unsaturated soils. Soil Science Society of America Journal, v.44, p.892-898, 1980.

41 VAN GENUCHTEN, M.Th.; LEIJ, F.J.; YATES, S.R. The RETC code for quantifying the hydraulic functions of unsaturated soils. Riverside: US Salinity Laboratory, 1991. 93 p.

42 VIEIRA, S.R. Permeâmetro: novo aliado na avaliação de manejo do solo. O Agronômico, v.47/50, p.32-33, 1998

43 VISSOTTO JÚNIOR, D. Modelagem numérica para interações superfície-atmosfera no estado do Paraná. Curitiba, 2003. 174 p. Dissertação (Mestrado em Métodos Numéricos em Engenharia) - Universidade Federal do Paraná.

44 ZEHE, E.; FLÜHLER, H. Preferential transport of isoproturon at a plot scale and a field scale tile-drained site. Journal of Hydrology, v.247, p.100-115, 2001.

45 WAUCHOPE, R.D. The pesticide content of surface water draining from agricultural fields - a review. Journal of Environmental Quality, v.7, p.459-472, 1978.

46 WESSELING, J.G. Meerjarige simulaties van grondwaterronttrekking voor verschillende bodemprofielen, grondwatertrappen en gewassen met het model SWATRE. Wageningen: Winand Staring Centre, 1991. (Winand Staring Centre, Report 152). 


\section{AGRADECIMENTOS}

À FUNDECT (Fundação de Apoio ao Desenvolvimento do Ensino, Ciência e Tecnologia do Estado de Mato Grosso do Sul) pela concessão do auxílio financeiro que possibilitou a realização desse trabalho. Ao CREA/ MS, em Campo Grande, que possibilitou o acesso aos receituários agronômicos. 